\title{
Uma leitura sobre abordagens de avaliação, a partir da análise da prática de avaliadores
}

\section{Introdução}

O Instituto Fonte e a Fundação Itaú Social realizam desde 2008 uma parceria cujo objetivo é promover o fortalecimento do campo de avaliação de iniciativas sociais - especialmente de organizações da sociedade civil. A premissa é de que a avaliação contribui para o desenvolvimento de tais iniciativas, qualificando-as e oferecendo não só às organizações a possibilidade de melhorar seus processos e resultados mas também às equipes a oportunidade de se apropriarem de suas práticas.

Ao longo dos anos, a parceria realizou diversas pesquisas, a partir das quais se uniram o Instituto Paulo Montenegro e o Instituto Brasileiro de Opinião Pública e Estatística Inteligência (IBOPE Inteligência), possibilitando a ampliação e qualificação dessas pesquisas. Entre elas, destacam-se a pesquisa realizada com organizações da sociedade civil (OSCs) sobre suas compreensões e práticas de avaliação (FIS, IBOPE, IF e IPM, 2009) e a pesquisa que apresen- tamos aqui, com profissionais que atuam na área de avaliação, sobre seus perfis, suas articulações e suas abordagens.

Além de pesquisas, a parceria promove eventos (os "diálogos") sobre temas relevantes e atuais relacionados à avaliação de iniciativas sociais, assim como a sistematização de casos e a disseminação de conhecimento em eventos nacionais e internacionais. O contato com diversos atores e os estudos no campo da avaliação culminaram na necessidade de uma pesquisa sobre as abordagens existentes nesse campo de atuação no Brasil.

Por um lado, a pesquisa com as OSCS (FIS, IBOPE, IF e IPM, 2009) revelou que tais organizações reconhecem a importância de se fazer avaliação, que elas empreendem esforços próprios para realizarem ações nesse sentido, mas que o uso da avaliação ainda carece de sentido para a própria iniciativa, permanecendo como 
uma obrigação formal ou como um instrumento de promoção dos projetos - e não como ferramenta de gestão. Esses achados indicaram a necessidade de conhecer mais profundamente o que está sendo feito na prática das avaliações.

A princípio, poderíamos proceder a essa caracterização a partir de publicações em revistas e livros relacionados com avaliação, mas por uma escolha epistemológica e também circunstancial, a pesquisa sobre as abordagens baseou-se na análise de práticas de profissionais que atuam com avaliação.

Originalmente, a tentativa era construir um paralelo com o modelo construído por Alkin $(2004,2012)$ para caracterizar a "Árvore das teorias da Avaliação", que apresenta uma estrutura conceitual para situar os diferentes teóricos do campo da avaliação, compreendendo que cada um deles representa uma abordagem teórica dentro de grandes ramos da avaliação. Em sua compreensão, há três grandes ramos de avaliação: uso, método e julgamento. A caracterização se baseia na resposta hipotética à questão "Quando o avaliador tiver que fazer concessões, do que ele abriria mão mais facilmente e o que ele defenderia mais tenazmente?". Inicialmente, o autor localizou teóricos avaliadores dos EUA, Europa, Austrália e Nova Zelândia. Mais recentemente, Alkin e Cardem (2012) buscaram aplicar o mesmo modelo conceitual para abordagens presentes no que eles chamaram de LMICs (low and middle income countries - países com renda baixa e média), reconhecendo algumas limitações em sua análise e no conhecimento que se tem sobre as abordagens nesses países por conta da escassez de publicações e da consequente formalização dessas abordagens em artigos e textos acadêmicos. Também reconhecem que há abordagens nascendo da prática nesses países e que há a dificuldade de identificar "fundadores" específicos, já que muitas vezes elas nascem de uma prática coletiva.

As abordagens às quais chegamos a partir das análises dos dados sobre os profissionais que atuam com avaliação mostram paralelos com esse modelo, porém não se equivaleram a ele, principalmente porque o objeto de Marvin Alkin tem sido a produção teórica escrita, enquanto o objeto da construção aqui realizada é a prática. Essa escolha possibilitou mais abrangência ao estudo, caso contrário, nos limitaríamos aos avaliadores que atuam dentro do esquema mais acadêmico, priorizando pesquisas, publicações de artigos, etc., o que não reflete a grande parte dos profissionais que atuam com avaliação no Brasil, a despeito de sua formação acadêmica e seu vínculo com a pesquisa. Não buscamos aqui fazer uma oposição entre prática e teoria, mas reconhecer que cada uma tem a sua especificidade e, como em Schwandt (2005), definimos e compreendemos a prática como um empreendimen- 
to diferente da aplicação da teoria, já que tem dinâmicas e lógicas próprias:

"A broader definition of evidence-based suggests that practice is more than a site or context for the application of scientific knowledge. It is compatible with the view that practice is a very complex affair involving the practitioner together with the student, employee, client, patient or service user in a joint decision-making process that involves simultaneous consideration of evidence, professional values, political considerations and individualized goals (...) Practice, as understood here, is a particular kind of human engagement that involves one's dealing with, or interactions with, others that unfold in view of some particular understanding of substantive rationality appropriate to the practice in question." (Schwandt, 2005, p. 98)

Escolhemos, então, caracterizar as abordagens de avaliação no Brasil a partir da análise das práticas de avaliadores reconhecidos como referências do campo da avaliação de iniciativas.

A escolha foi de realizar esse estudo partindo-se da visão dos profissionais que estão envolvidos na condução das avaliações, os chamados "avaliadores".

Os objetivos desta pesquisa foram, então, construir um perfil do profissional que atua com avaliação, compreender suas articulações dentro do campo e mapear as abordagens presentes no campo da avaliação de iniciativas sociais no Brasil, a partir da prática desses profissionais.

\section{Método}

O primeiro passo foi a realização de um estudo quantitativo com o intuito de: a) produzir uma caracterização do perfil básico dos profissionais que atuam com avaliação, considerando-se formação, tempo de experiência, áreas de atuação e declaração de abordagem; e b) colher indicações entre pares (por meio de metodologia chamada "bola de neve ${ }^{3 "}$ ), de forma a construir um painel de informantes-chave possíveis para serem entrevistados.

O ponto de partida foi a pesquisa com OSCs (FIS, IBOPE, IF e IPM, 2009), que indicaram profissionais contratados para a realização de suas avaliações, a partir dos quais chegou-se a uma lista inicial de avaliadores, que por sua vez indicaram colegas e assim por diante. Dessa forma, a pesquisa alcançou de forma mais direta os profissionais que atuam no chamado "terceiro setor".

Foi aplicado um questionário semi-estruturado a partir de entrevistas via CATI (Computer Assisted Telephone Interview) realizadas pelo IBOPE Inteligência com perguntas sobre formação, atuação, conceitos e valores relacionados à avaliação e indicações de nomes de colegas e referências no campo.

O segundo passo foi a realização de uma análise de rede a partir das indicações para a construção do painel de informantes-chave. Os critérios que embasaram a seleção de entrevistados foram:

- Relevância: profissionais-referência para a rede ou para grupos específicos; 
- Heterogeneidade: profissionais de diferentes grupos, abordagens ou segmentos da rede.

A partir da aplicação desses critérios ${ }^{4}$ e do conhecimento sobre o campo das organizações parceiras, foram selecionados 16 profissionais para ser entrevistados.

Finalmente, o terceiro passo foram as entrevistas em profundidade com esses profissionais. Foram entrevistados 16 profissionais, a partir de um roteiro de perguntas orientado aos seguintes temas:

- A formação e a trajetória profissional de cada entrevistado no campo da avaliação, assim como pessoas e referências que o influenciaram;

- A prática em avaliação de iniciativas sociais, a partir da exposição detalhada de um ou mais casos concretos;

- Valores, princípios e critérios de qualidade da avaliação de iniciativas sociais;

- A articulação com outros profissionais que atuam no campo;
- O olhar sobre o campo, desafios presentes e oportunidades.

Todas as entrevistas foram gravadas e transcritas. Em dois casos, a entrevista foi feita por escrito. A análise de cada entrevista focou a caracterização das influências e da trajetória; a prática de avaliação do profissional; as premissas e os valores implícitos na prática do profissional; o tipo, intensidade de articulação e colaboração com outros profissionais; e o levantamento de leituras sobre o campo da avaliação.

\section{Resultados}

Os resultados são apresentados em três blocos, considerando: 1) o perfil do avaliador; 2) as articulações entre os avaliadores; 3 ) as abordagens encontradas.

\section{O PERFIL DO AVALIADOR}

Foram identificados um total de 279 profissionais a partir das indicações iniciais de organizações da sociedade civil que realizaram avaliações entre 2004 e 2009 e das indicações entre avaliadores.

3 A metodologia de "Bola de Neve" é uma forma de construção de uma amostra não probabilística utilizada em pesquisas sociais, na qual os participantes iniciais de um estudo indicam novos participantes, que, por sua vez, indicam novos participantes e assim sucessivamente, até que seja alcançado o "ponto de saturação", quando os novos entrevistados passam a repetir os conteúdos já obtidos em entrevistas anteriores.

4 Para a operacionalização desses critérios foram utilizadas as medidas de centralidade dos atores na rede. 0 primeiro foi a "centralidade de grau" (degree centrality), que calcula o número de vínculos adjacentes para cada ator da rede. O segundo foi o parâmetro de intermediação (betwennesscentrality), que identificam atores que desenvolvem um papel de "ponte" devido ao fato de se encontrarem entre outros atores e, dessa forma, poderem conectar pedaços inteiros da rede. O terceiro e último foi a medida chamada de "prestígio", indicada pela direção e número de citações.

Revista Brasileira de Monitoramento e Avaliação | Número 3 | Janeiro-Junho de 2012 


\section{FIGURA 1: DISTRIBUIÇÃO DA AMOSTRA POR FAIXA ETÁRIA}

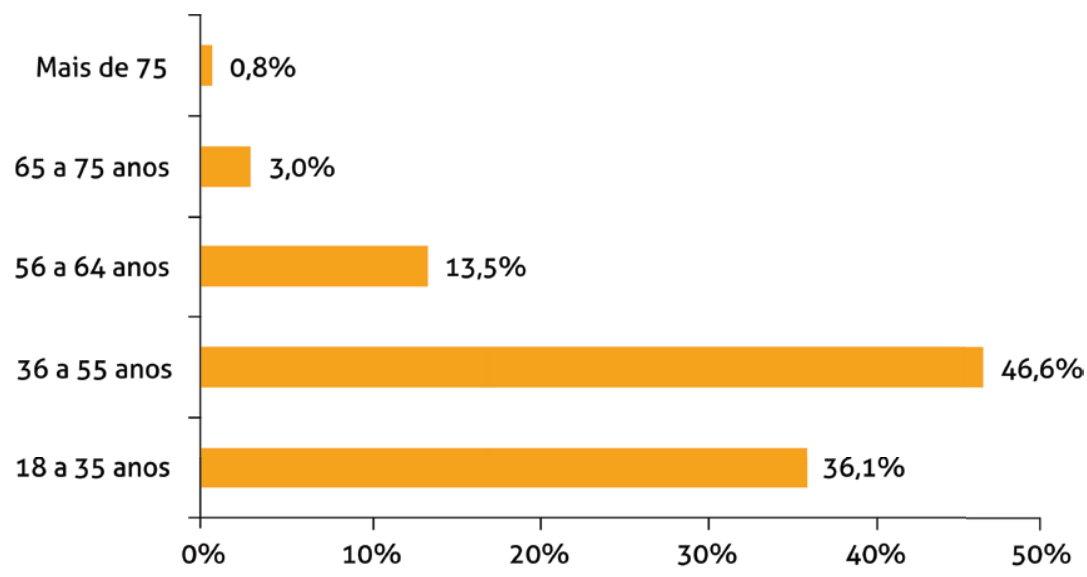

Fonte: Pesquisa IBOPE/ 2011

Deste conjunto, 133 (47,7\%) responderam a um questionário via CATI (Computer Assisted Telephone Interview) aplicado pelo IBOPE Inteligência. Os dados da fase quantitativa da pesquisa revelam um perfil do avaliador com uma média de 42 anos e uma concentração na faixa entre os 36 e 55 anos (Figura 1), predominantemente feminino (68\%) e com em média nove anos de atuação em avaliação.

Em relação ao vínculo institucional, a amostra revela que $58 \%$ dos entrevistados trabalham em uma organização que presta serviços de avaliação para terceiros (que podem ser organizações públicas, privadas ou OSCs), $45 \%$ trabalham em uma organização fazendo avaliação das suas iniciativas e $30 \%$ atuam como autônomos para diversas organizações, evidenciando que uma parcela dos avaliadores atua tanto dentro quanto fora do próprio ambiente institucional.
Os clientes de avaliação dos avaliadores são organizações não governamentais (83\%), empresas privadas (49\%), organizações públicas (40\%), universidades $(29 \%)$, jornais/revistas (8\%) e organizações internacionais (3\%). 0 índice de multiplicidade 2,2 reforça uma imagem do avaliador diversificado em termos de atuação, o que se confirmará com os dados de formação e áreas de atuação. Esse dado também mostra que, apesar de termos originado nossa "bola de neve" com indicações de OSCs, os profissionais pesquisados não atendem somente a esse setor.

Os dados amostrais apresentados na Figura 2 mostram que $99 \%$ ao menos iniciaram a formação superior e $65 \%$ têm algum curso de pós-graduação, conformando um elevado nível em termos de escolaridade: 


\section{FIGURA 2: DISTRIBUIÇÃO DA AMOSTRA POR NÍVEL DE ESCOLARIDA}

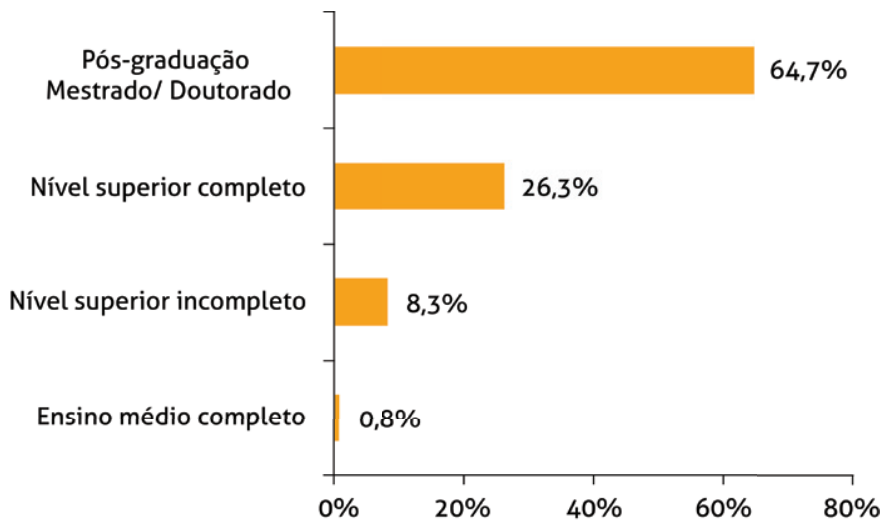

Fonte: Pesquisa IBOPE/ 2011

Em relação às áreas de formação, notamos uma grande diversidade. Há um predomínio nas áreas sociais e educacionais, com a presença significativa, porém, das mais diversas especialidades. Temos desde pedagogia, psicologia, ciências sociais, até administração, economia, medicina, biologia, geografia, geologia, engenharias, entre outros. Foram citadas mais de vinte carreiras. Esses dados indicam que a atuação na área de avaliação parte de um conjunto amplo de formações, não havendo um padrão específico.

Com relação aos dados relacionados à área de atuação dos projetos com os quais trabalham os avaliadores, a diversidade se repete, como notamos pelo índice de multiplicidade (em média cada avaliador apontou para 4,2 áreas) e pela distribuição de temas, na Figura 3:

\section{FIGURA 3: ÁREA DE ATUAÇÃO EM AVALIAÇÃO DO PROFISSIONAL}

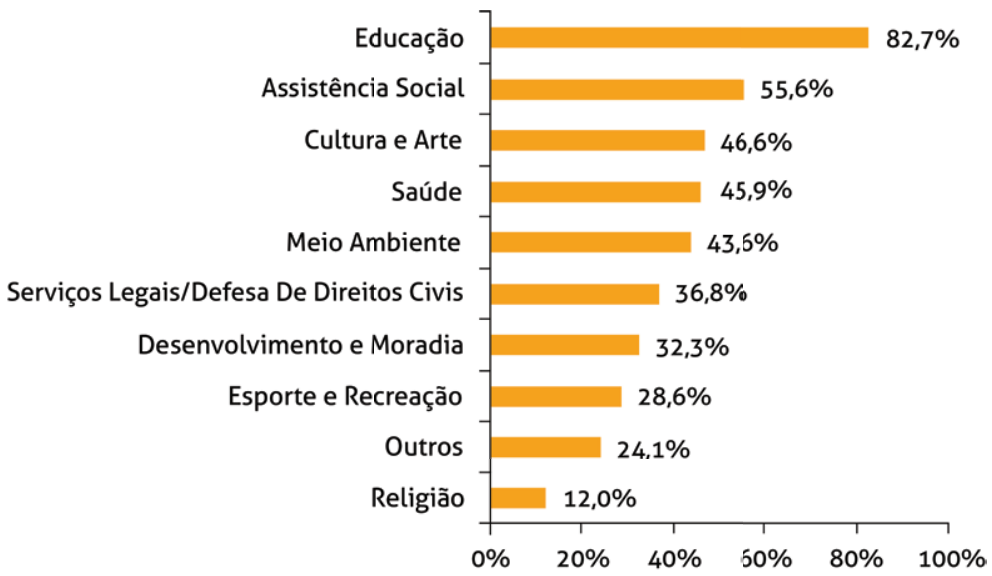

Pesquisa IBOPE/ 2011

Revista Brasileira de Monitoramento e Avaliação | Número 3 | Janeiro-Junho de 2012 
Relacionando área de formação com área de atuação em avaliação, observamos um alinhamento, sendo que as principais áreas de formação são pedagogia, sociologia/ ciências sociais, psicologia/psicologia social e serviço social, e as principais áreas de atuação são educação e assistência social. Por outro lado, observamos uma grande parte dos avaliadores que atua "fora" da sua área de formação, o que é evidenciado pelo índice de multiplicidade (atuação em 4,2 áreas para cada avaliador). Esses dados sinalizam um perfil profissional que adapta a sua área de atuação conforme a demanda, sem especialização em uma área só. Isso não significa que não haja especificidades no perfil do avaliador e nas suas competências para atuar com avaliação, mas sim que essa especificidade não está relacionada a uma área do conhecimento.
No que se refere ao histórico profissional e de formação dos avaliadores, a análise das entrevistas em profundidade revelou trajetórias dos profissionais que, por sua vez, refletem também habilidades presentes no perfil do avaliador. A figura abaixo busca sistematizar essas experiências com as competências encontradas nos avaliadores em maior ou menor grau: sensibilidade a questões sociais, capacidade de negociar interesses, competência em investigação e facilitação de aprendizagem.

Cada profissional varia na intensidade com que percorreu cada uma das experiências e no grau com que desenvolveu e utiliza cada uma das competências em sua atuação. Porém, a partir da análise das práticas e dos discursos dos avaliadores, tais aspectos estão presentes no ato de avaliar iniciativas sociais e o avaliador, como responsável

\section{FIGURA 4: ESOUEMA DAS EXPERIÊNCIAS E HABILIDADES ENCONTRADAS NOS AVALIADORES}

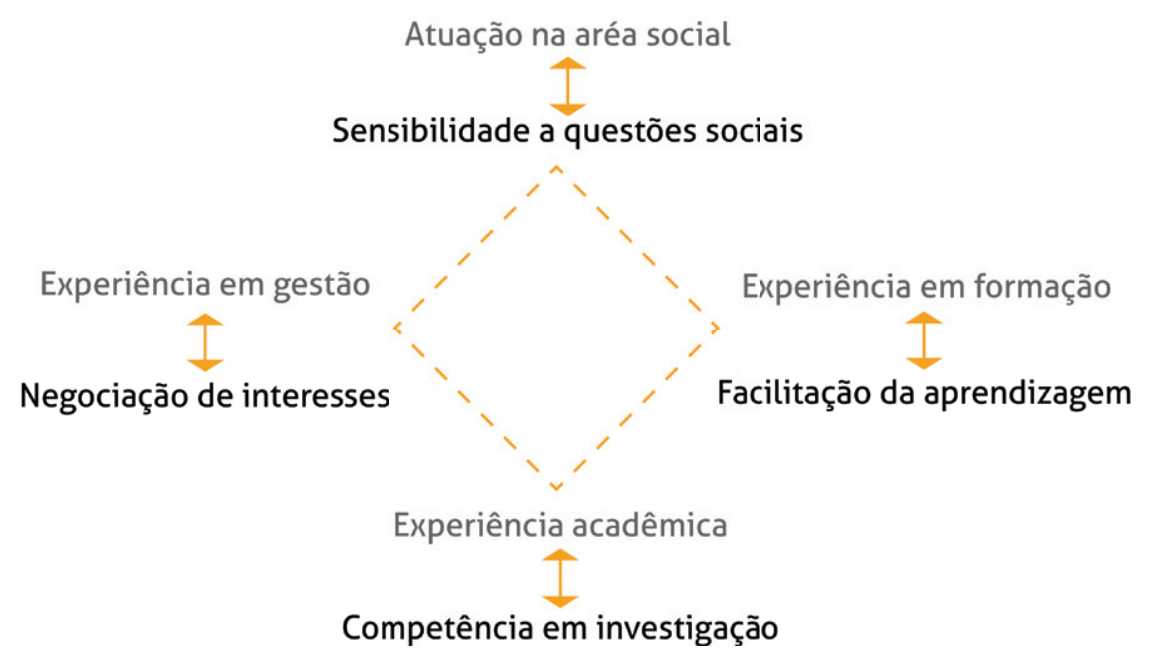


pelo processo, mobiliza essas capacidades em prol de seu bom andamento. Entendemos a experiência como um acontecimento histórico na trajetória do avaliador e a capacidade como uma habilidade específica desenvolvida a partir dele.

A atuação na área social relacionada à sensibilidade a questões sociais emergiu como uma habilidade presente ao avaliador. Nas trajetórias dos profissionais entrevistados, a atuação na área social apareceu frequentemente como experiências de militância junto a movimentos sociais diversos, ou ainda como um interesse acadêmico pela investigação de questões sociais, tais como a desigualdade social, o Índice de Desenvolvimento Humano (IDH), o acesso à educação, entre outras.

No vértice abaixo, vemos a experiência do profissional na área acadêmica, possibilitando o desenvolvimento de competências em investigação e métodos de pesquisa. 0 profissional que atua com avaliação, como visto nos dados sobre formação e também nas entrevistas, tem uma base importante de sua constituição na experiência com pesquisa realizada em ambiente acadêmico, seja nas próprias experiências de formação, como mestrado, doutorado e pós-doutorado, seja nas experiências como docente e pesquisador. É praticamente unânime entre os avaliadores a experiência acadêmica e de pesquisa.

Outra experiência que ajuda a formar um avaliador é a de gestão de iniciativas (pro- jetos, programas ou mesmo instituições), presente em muitas trajetórias dos entrevistados em profundidade. Em alguns casos, inclusive, o profissional esteve à frente de avaliações internas realizadas na iniciativa em que fazia também a gestão. Essa experiência esteve relacionada à habilidade de trabalhar com processos de negociação de interesses e valores sempre presente em processos de avaliação - e ao diálogo dentro de equipes de trabalho ou dentro das instituições. Essa habilidade emergiu relacionada à direção das avaliações para processos decisórios. A habilidade do avaliador em facilitar negociações esteve relacionada, nos relatos, à vinculação da avaliação ao processo de elaboração de mudanças organizacionais e estratégicas dos projetos ou programas.

Finalmente, encontramos em trajetórias de avaliadores a experiência em formação e que, nos casos representados pelos entrevistados, significam tanto experiência em educação popular como o ensino em universidades e oficinas de cursos não formais, entre outros. A experiência com formação está vinculada à habilidade de facilitar processos de aprendizagem, presente em boa parte dos avaliadores. Nesses casos, ao mesmo tempo em que apoia a avaliação, o profissional cumpre o papel de capacitar a equipe envolvida, seja em métodos e técnicas de avaliação strictu-sensu, seja em habilidades mais amplas que também se relacionam com avaliação, como reflexão a partir da prática, capacidade de observação e análise, entre outros. 
FIGURA 5: FREOQUÊNCIA DE ATIVIDADES DESENVOLVIDAS PELOS AVALIADORES

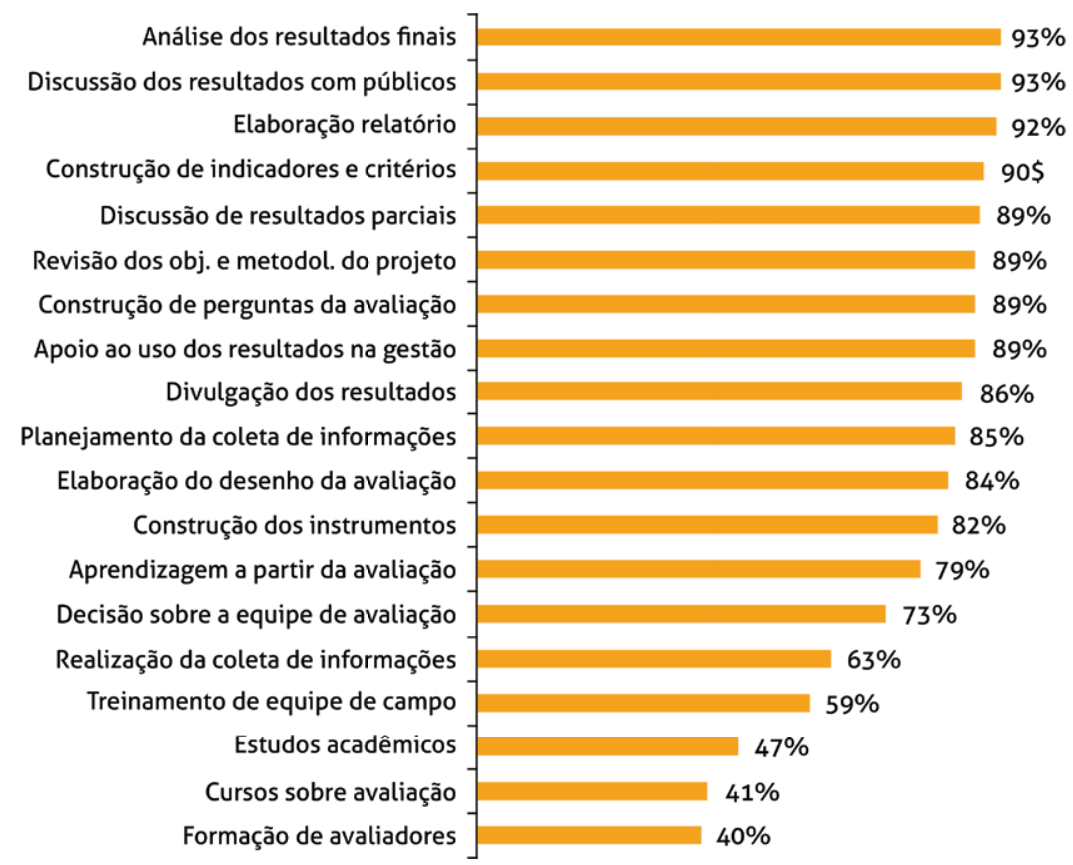

Fonte: Pesquisa IBOPE/ 2011

Os dados quantitativos relacionados com a participação do avaliador nas diferentes atividades da avaliação mostram, novamente, um profissional "multitarefas", já que se envolve em uma média de 14,7 atividades dentro daquilo que entende ser todo o processo de avaliação, como vemos na Figura 5.

As atividades mais citadas pelos avaliadores foram análise dos resultados finais e discussão dos resultados com públicos interessados, com 93\% dos avaliadores e elaboração de relatório, com o envolvimento de $92 \%$ dos avaliadores. As atividades que contaram com o menor envolvimento foram estudos acadêmicos (47\%), cursos sobre avaliação (41\%) e formação de avaliadores (40\%) - todas mais diretamente relacionadas à pesquisa e formação tendo a avaliação como objeto do que à reali- zação de ações do processo de avaliação propriamente dito. $\mathrm{O}$ envolvimento mais frequente do profissional na realização de avaliações do que na investigação sobre avaliação é uma característica frequente dos profissionais que atuam no campo e que também deixa suas marcas na escassez de estudos sobre avaliação, em comparação à alta frequência de estudos avaliativos $^{5}$.

Em termos de formação específica em avaliação, metade (51\%) declara ter feito algum curso em avaliação de projetos e programas sociais. Entre os cursos mencionados pelos entrevistados encontram-se cursos "formais" em universidades, assim como cursos e workshops informais promovidos por organizações não governamentais, associações e organizações financiadoras. As mais citadas são apresentadas na Tabela 1: 
TABELA 1: CURSOS DE AVALIAÇÃO INDICADOS PELOS PROFISSIONAIS

\begin{tabular}{lr} 
Instituição de ensino & No de indicações \\
Fundação Itaú Social & 15 \\
\hline GIFE & 9 \\
\hline Instituto Fonte & 9 \\
\hline USP & 7 \\
\hline PUC & 6 \\
\hline Fonte: Pesquisa IBOPE/ 2011 &
\end{tabular}

Estes dados indicam um campo de profissionais que aprendem a fazer avaliação dentro de suas formações em áreas acadêmicas específicas e também a partir da prática e de estudos "informais". Também refletem a escassez de formações específicas em avaliação no País ${ }^{6}$.

Como resultado, traça-se o perfil do avaliador como um profissional versátil que se envolve em múltiplas atividades, especialmente no processo de análise, discussão e divulgação dos resultados. O profissional que atua com avaliação desenvolve-se em competências variadas. Apesar de ter um grau alto de escolaridade, metade tem formação específica em avaliação. Estes dados dialogam com a imagem de avaliação como uma transdisciplina - uma área de conhecimento transversal, que passa entre, além e através das disciplinas ${ }^{7}$. Neste sentido, o avaliador brasileiro adapta-se para atuar dentro desta transdisciplina. Por outro lado, mesmo sendo uma disciplina que serve outras disciplinas, a questão que emergiu entre os entrevistados e a partir da análise dos dados refere-se ao sentido e à necessidade de existência e reconhecimento da avaliação também como uma disciplina em si mesma, garantindo discussões sobre sua conformação histórica, ética e metodológica específica. Os dados sobre a articulação dos avaliadores nos trazem mais alguns elementos para alimentar esse debate.

\section{A ARTICULAÇÃO ENTRE AVALIADORES COMO METÁFORA DE FUNCIONAMENTO DO CAMPO DE AVALIAÇÃO}

Inicialmente, a coleta de indicações entre profissionais e a análise dessas articulações visava chegar a um conjunto relevante de profissionais que pudessem ser entrevistados e trouxessem suas abordagens e práticas de forma a representar o campo como um todo. Tal amostra não significaria uma amostra probabilística, mas sim uma amostra social relevante, politicamente dentro do conjunto de avaliadores e, especialmente, expressaria diferentes subgrupos. Porém, essa análise mostrou-se também relevante para a construção de hipóteses sobre o funcionamento do campo

5 Um estudo realizado pelo Projeto Avaliação com Dissertações e Teses confirma essa informação. Instituto Fonte (2008).

6 O Projeto Avaliação está realizando um levantamento nesse sentido, que poderá ser visto na página: www.institutofonte.org.br/projeto-avaliacao.

7 (Scriven, 2003, Heberger, Christie \& Alkin, 2010.)

Revista Brasileira de Monitoramento e Avaliação | Número 3 | Janeiro-Junho de 2012 
da avaliação de iniciativas sociais no Brasil - tanto no que se refere às suas dinâmicas de troca, aprendizagem entre pares e meta-avaliações quanto nas suas dinâmicas de produção de conhecimento teórico e construção de referenciais éticos.

É necessário fazer algumas ressalvas sobre a coleta de dados sobre articulação, a análise de redes sociais e o fenômeno que estávamos buscando investigar: a rede de profissionais que atuam com avaliação. Em primeiro lugar, a coleta de indicações não foi exaustiva, compreendemos que a análise permitiu a visualização da "ponta do iceberg", de forma que se continuássemos colhendo indicações, poderíamos ter chegado a mais conexões. Outra observação é que o fenômeno empírico "a rede de avaliadores" é dinâmico - novas relações e novos atores se constituem a cada momento. A análise retrata um momento do fenômeno, faz uma fotografia de um instante. Essa análise tampouco revela de forma mais profunda a qualidade das relações.

Finalmente, ao trabalhar com a ferramenta de análise de redes sociais ${ }^{8}$ estabelece- mos um constructo hipotético, qual seja, a existência da própria rede de avaliadores, afinal podemos perguntar "Existe uma rede social de avaliadores?". Optamos por levar essa assunção adiante, considerando essa rede como o conjunto de profissionais identificados e as relações entre eles. Também compreendemos que essa rede existe na medida em que compartilha uma prática profissional e, em alguma medida, uma (in) certa identidade de "avaliador". Todos os entrevistados nas fases quantitativa e qualitativa se identificaram como profissionais que atuam com avaliação, apesar de terem, muitas vezes, crenças diferentes sobre o que é esta prática. Nossa premissa foi de que essas diferenças integram a própria avaliação, como campo multidisciplinar.

Dessa forma, a equipe do IBOPE Inteligência: 1) coletou indicações de profissionais que trabalham com avaliação, por telefone, com OSCs que tinham realizado alguma avaliação nos últimos 5 anos; 2) Entrevistou e colheu mais indicações entre os profissionais, e; 3) repetiu o último procedimento mais uma vez. Os dados de campo foram os seguintes:

\section{TABELA 2: DADOS RELACIONADOS ÀS INDICAÇÕES ENTRE PROFISSIONAIS DURANTE A ETAPA DE COLETA}

\begin{tabular}{lll} 
& $1^{\text {a }}$ RODADA & 2 $^{\text {a RODADA }}$ \\
Cadastro inicial de profissionais & 174 & 120 \\
\hline Número de respondentes & 131 & 37 \\
\hline Total de indicações & 147 & 58 \\
\hline Nenhuma indicação & $42 \%$ & $11 \%$ \\
\hline Média de indicações & 1,9 & 1,75 \\
\hline Novos nomes & 120 & 54 \\
\hline Total de questionários completos & & 133 \\
\hline
\end{tabular}

Fonte: Pesquisa IBOPE/2011. 
TABELA 3: INDICADORES DA REDE DE AVALIADORES

\begin{tabular}{lc} 
Indicadores & Números \\
\hline Tamanho 1 (nº de indivíduos com isolados) & 279 \\
\hline Tamanho 2 (nº de indivíduos sem isolados) & 233 \\
\hline No de Vínculos & 388 \\
\hline Densidade & $1,67 \%$ \\
\hline Distância média entre indivíduos (em "passos") & 5,43 \\
\hline Grau Mínimo (vínculos por indivíduo) & 1 \\
\hline Grau Máximo (vínculos por indivíduo) & 8 \\
\hline
\end{tabular}

Fonte: Pesquisa IBOPE/2011.

FIGURA 6: REPRESENTAÇÃO GRÁFICA DAS ARTICULAÇÕES ENTRE OS AVALIADORES

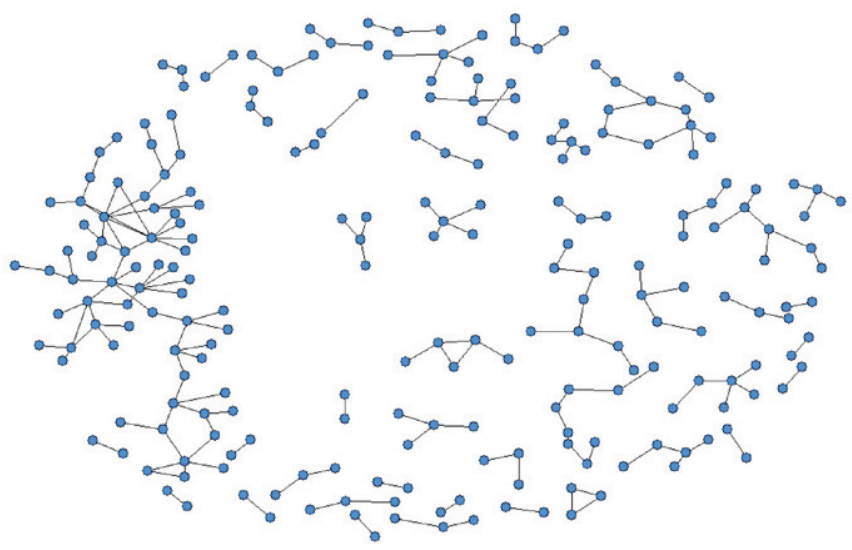

Fonte: Pesquisa IBOPE/2011

Tantos os dados de campo quanto os indicadores gerais da rede (ver tabela 3 acima) sinalizam uma rede com baixos níveis de articulação.

Os indicadores de articulação e a representação gráfica apontam para uma rede fragmentada, com a existência de um grupo maior e mais denso de relações entre os profissionais que o compõem, e diversos outros grupos menores com profissionais articulados entre si, mas não articulados com outros grupos. Essa imagem da rede retrata um campo em que coexistem fortemente grupos pequenos (cinco ou seis indivíduos que atuam com avaliação) que se articulam internamente, mas não articulados com outros. Uma análise

8 Para isso foi utilizado um software chamado UCINET (Software for Social Network Analysis), desenvolvido em sua versão 5.0 pela Universidade de Harvard, nos EUA.

Revista Brasileira de Monitoramento e Avaliação | Número 3 | Janeiro-Junho de 2012 
superficial dos grupos indicou a formação do grupo maior e mais articulado de profissionais atuantes no Rio de Janeiro e em São Paulo, muitos consultores ou organizações especializadas no apoio a OSCs e a investidores privados. As entrevistas em profundidade com profissionais pertencentes a este grupo maior relevaram trajetórias semelhantes, frequentemente com formações nos EUA, com membros da American Association Evaluation (www. eval.org) e participações em congressos anuais e cursos dessa associação.

Entre os representantes dos grupos menores, emergem especialmente pesquisadores ligados às universidades, que adaptam ou criam abordagens a partir de suas pesquisas, cursos e especialidades. São profissionais dentro de sub-redes, identificados como referências pelos seus colegas próximos e responsáveis pela articulação interna nesses subgrupos. Esses avaliadores são referências setoriais, "especialistas" em determinadas abordagens ou temas específicos.

A baixa densidade e a fragmentação indicam uma articulação limitada entre os distintos grupos de profissionais que formam o campo da avaliação. Esta imagem é reforçada nas entrevistas em profundidade, nas quais vários entrevistados trazem percepções sobre a existência de "nichos" que conversam pouco entre si.

Praticamente todos os entrevistados relatam a escassez de troca de conhecimento entre os próprios profissionais que atuam com avaliação para além de um círculo restrito. Parte relata falta de tempo para dedicar-se a estudar e a dialogar com pro- fissionais de outras abordagens ou mesmo com outros profissionais de maneira geral. Outros relatam também o desconhecimento de oportunidades em que possa acontecer essa troca.

Segundo diversos entrevistados, o campo está muito competitivo, já que nos últimos anos houve uma expansão da demanda por avaliações, mas também um aumento no número de profissionais que se colocam para atender a essa demanda. Por isso, a pouca articulação poderia representar uma leitura de alta competitividade no setor.

A principal contribuição da análise de rede no aprofundamento da compreensão sobre o avaliador e sua atuação é o reconhecimento de que apesar da pouca formalidade do campo da avaliação no Brasil, há um número grande de profissionais que atuam dentro dele, já extenso na amostra recolhida, mas certamente maior do que o levantado nesta pesquisa. De qualquer maneira, a rede indica um baixo nível de interação entre os profissionais e ainda é preciso aprofundar a compreensão sobre o significado deste padrão. Porém, o reconhecimento de articulações entre profissionais e a identificação daqueles que são referência em avaliação contribuíram para a identificação de um campo profissional e de diferentes abordagens existentes dentro dele.

\section{ABORDAGENS A PARTIR DA PRÁTICA}

A partir da análise das entrevistas, da identificação de trajetórias formativas, das habilidades presentes no avaliador e das suas 
práticas e premissas profissionais foi possível caracterizar abordagens. Compreendemos aqui como abordagem um conjunto de aspectos - como premissas e valores, preferência por determinados métodos de investigação, envolvimento dos stakeholders e processos de discussão dos resultados da avaliação - que caracterizam um padrão de prática profissional. Essas práticas profissionais mantêm relação com referenciais teóricos, mas não se definem por eles. De fato, a coleta de referenciais entre os entrevistados originou um espectro diverso de teorias que embasam as diferentes abordagens de forma bastante heterogênea, de modo que os aspectos comuns dentro das abordagens se dão prioritariamente pelas práticas em detrimento da identificação com essa ou aquela teoria. Comentários específicos sobre marcos teóricos dentro de cada abordagem são tecidos dentro da caracterização de cada abordagem.

As abordagens encontradas foram três: a avaliação orientada pela investigação, $a$ avaliação orientada à tomada de decisões e a avaliação orientada à aprendizagem. Esses nomes foram criados a partir da identificação da orientação central do processo de avaliação conduzido e não refletem denominações atribuídas pelos próprios avaliadores. Para caracterizar as abordagens, lidamos com uma pergunta semelhante à utilizada por Alkin (2004), mas adaptada a este estudo: "Se a avaliação tivesse que abrir mão de algum di- recionamento, qual seria aquele do qual a abordagem se ateria mais tenazmente? De que direcionamento não se abre mão?". As abordagens encontradas também revelam a premissa de que, em maior ou menor grau, todas as avaliações lidam sempre com precisão investigativa, apoio à tomada de decisão e aprendizagem, porém a depender da abordagem um direcionamento pode se sobrepor a outro, pois nem sempre cada uma dessas prioridades caminha junto com a outra.

Apesar das diferenças que existem entre as abordagens em relação às suas prioridades, focos e estratégias investigativas, todas elas se enquadram na definição mais ampla de avaliação feita por Scriven há décadas: "Evaluation is the process of determining the merit, worth and value of things and evaluations are the products of that process $^{\prime \prime}$. Todas as abordagens aqui retratadas lidam com o ato de avaliar como construção de subsídios para, ou o próprio ato de, atribuir mérito, valor ou relevância a uma iniciativa, projeto ou programa. Importante notar também que apesar de cada profissional ser bastante afirmativo com relação à sua prática, suas crenças e abordagens, também tem clareza sobre os limites de sua atuação. Nesse sentido, conhecem melhor os limites de sua própria abordagem que as possibilidades de outras. Ao apresentar cada uma das abordagens, trazemos também os limites indicados pelos próprios profissionais entrevistados. 
A seguir apresentamos as abordagens encontradas. Para caracterização de cada uma delas, partiu-se da definição do direcionamento dado, das características da atuação dentro dela e de uma concepção básica do processo de avaliação dividido em três etapas centrais:

- A contextualização e construção do foco da avaliação, compreendida como a etapa de definição dos conteúdos centrais que a avaliação abordará na sua fase de investigação. Nesta etapa, são definidos objetivos, perguntas de avaliação, indicadores, critérios e outros parâmetros utilizados para definir "para onde" a avaliação voltará sua atenção.

- A investigação propriamente dita, compreendida como a etapa de construção do desenho investigativo, dos instrumentos de coleta e da coleta de informações. Nesta etapa, há escolhas também sobre a utilização de metodologias quantitativas ou qualitativas.

- A análise e discussão dos resultados, na qual são discutidos os achados da avaliação, é elaborado um relatório ou apresentação, e são discutidas possíveis recomendações. Nessa etapa, os profissionais podem ou não se envolver na construção de recomendações ou mesmo na discussão de futuras modificações na iniciativa a partir da avaliação.

Também são apresentadas "considerações sobre a abordagem", nas quais são trazidas reflexões sobre os ganhos e os desafios encontrados por cada uma das abordagens.

\section{A) AVALIAÇÃO ORIENTADA PELA INVESTIGAÇÃO}

A avaliação orientada pela investigação é aquela que se constrói com base em uma proposta de investigação. Neste contexto, a avaliação é, acima de tudo, um processo de pesquisa sobre resultados de uma intervenção social, com o foco na precisão técnica no que concerne à investigação realizada. A principal questão que orienta essa prática é a de produzir conclusões precisas sobre as mudanças produzidas por uma dada intervenção, incluindo a refutação de que tais mudanças ocorreram por conta de outra ação que não a da iniciativa foco da avaliação.

Para os profissionais que atuam a partir desta abordagem, avaliação tem como eixo principal a pesquisa, compreendida como a produção científica de conhecimento. Seu trabalho é, portanto, zelar pela investigação, construir um desenho metodológico seguro e preciso, e chegar a conclusões comprováveis. Uma boa avaliação, nesta perspectiva, é caracterizada pela qualidade da investigação e pela segurança acerca dos achados produzidos. Nessa perspectiva, muitas vezes o conhecimento científico deve trazer aportes que a prática da iniciativa está necessitando:

"Às vezes você acha que todo mundo que você ajudou está bem-sucedido, mas mesmo se você não existisse eles estariam bem-sucedidos de todo jeito. Então é um autoengano. As pessoas tendem a acreditar que o que elas estão fazendo dá certo (...) mas isso não é necessariamente verdade. Elas podem 
ajudar o que está dando certo e procurar explicações quando não dá certo. Sem uma análise objetiva, um tratamento de controle, não dá para saber se efetivamente deu certo ou não."

De modo geral, as avaliações orientadas à investigação são realizadas por avaliadores que têm trajetórias de formação e introdução ao campo da avaliação marcadas pela pesquisa acadêmica e atuação como professores em instituições de ensino superior, especialmente nas áreas da Economia. A atuação acadêmica não é exclusividade desse perfil de avaliador, já que o elevado grau de formação e o vínculo com a pesquisa são marcas dos profissionais que atuam como avaliadores de forma geral. Porém, a intensidade dessa experiência para estes profissionais é superior. Tais profissionais têm marcada qualidade acadêmica, considerando-se os critérios de avaliação dessa atividade: número de publicações, publicações em revistas científicas reconhecidas, orientações, etc.

O foco do investimento em formação e atualização desses profissionais também é em leituras de artigos em revistas científicas e cursos acadêmicos (disciplinas em programas de mestrado, doutorado e outras inseridas no contexto universitário).

\section{O PROCESSO DA AVALIAÇÃO ORIENTADA PELA INVESTIGAÇÃO}

De modo geral, a contextualização e a construção do foco da avaliação são orientadas a identificar problemas de investigação relevantes passíveis de serem investigados cientificamente e também a identificar as condições necessárias para a realização desse processo investigativo e do melhor desenho. Muito desse processo pode ser caracterizado por compreender as variáveis presentes na situação: as produzidas pela intervenção ou os resultados (variáveis dependentes) e as que caracterizam a intervenção (variáveis independentes). Também há interesse em identificar a possibilidade e as condições para realizar comparação entre grupos, como a questão sobre a seleção dos beneficiários, quais critérios, procedimentos foram utilizados e a presença ou não de aleatoriedade na seleção.

A partir das entrevistas realizadas, vemos que o foco, nesta abordagem, costuma ser orientado a resultados da iniciativa e apoiado em critérios e indicadores quantitativos.

"A equipe tem que explicar qual a questão, qual o interesse, qual o contexto, como foi feito o projeto, como foi implementado, como foi escolhido quem ia ser beneficiado, todas essas coisas são muito importantes (...) Em termos de aplicação prática, aí cada avaliação tem a sua metodologia, né. A gente desenha a metodologia com base nas bases de dados que estão disponíveis. Se não tem linha de base, a gente faz uma metodologia que não precisa de linha de base. Se você tem linha de base, aleatorização, se você tem sorteio, aí a gente faz uma metodologia que usa aleatorização. Senão a gente usa a me- 
todologia com dados observacionais, entendeu? Então, a gente adapta a metodologia aos dados que estão disponíveis. Qualquer base de dados, qualquer exercício empírico vai ter uma base de dados específica com seus problemas e suas vantagens."

As análises dos dados são habitualmente realizadas a partir de técnicas estatísticas e econométricas. Seguindo essas análises, o avaliador elabora um documento com a síntese dos resultados e apresenta ao demandante, que pode solicitar aprofundamentos e novas análises. A partir daí, elabora-se um documento final e entende-se que o trabalho está finalizado.

"A gente faz uma apresentação e a partir da apresentação do financiador, o contratante faz perguntas para aprimorar a pesquisa, descobrir novos resultados, aí a gente refazer, faz o relatório final e entrega (...) Aí acabou."

Com relação às recomendações, há diferentes posições. Em alguns casos, não enxergam como papel do avaliador fazer recomendações, para não influenciar e manter a distância necessária. Em outros casos, percebem que a avaliação deve sim fazer recomendações, porém estas derivam diretamente das análises dos dados e resultados verificados, que apontam onde o programa ou o projeto está fraco ou forte.

\section{CONSIDERAÇÕES SOBRE A ABORDAGEM}

Os profissionais entrevistados apontam limites da abordagem da avaliação orientada pela investigação, por exemplo, que as investigações apontam claramente os resultados alcançados pela iniciativa, mas têm limites para relacioná-los com os processos que os produziram.

"Você sabe o impacto do projeto, sabe se afetou ou não. Muitas vezes, você não sabe o porquê, se houve uma falha no desenho, um mecanismos de implementação. Eu sugiro um outro tipo de pesquisa para complementar. Mas assim, eu só sugiro fazer uma pesquisa de monitoramento, uma pesquisa com os beneficiários, uma pesquisa qualitativa, que aí pode ajudar a entender os resultados alcançados (...) Acho que elas se complementam. Essa metodologia objetiva tem suas vantagens pelo fato de ser quantificável, ser objetiva, mas tem suas limitações também. Isso é importante deixar claro. Ela não resolve todos os problemas, as pessoas vêm a utilizar, combinar várias metodologias para entender o seu programa."

Também é destacado o fato de que, apesar de ser uma metodologia precisa e objetiva, não é um kit que é aplicado da mesma forma em qualquer situação.

"Então, cada avaliação é uma coisa específica. É aí que você tem que conversar com o cliente e entender o problema, né. Apesar de ser objetiva, não é um kit que você chega e aplica para toda situação porque cada avaliação é uma coisa completamente diferente da outra."

Por outro lado, os entrevistados chamam a atenção para um benefício da abordagem centrada em resultados e em técnicas estatísticas e econométricas como a objeti- 
vidade, a segurança nos achados e a sua confluência com a linguagem e os valores dos financiadores.

"Porque ela vai saber o impacto em termos objetivos, vai ter um número lá que é o resultado e ela tem facilidade, essa metodologia conversa bem com a linguagem dos financiadores muitas vezes, por ser mais objetiva, envolver números, por uma taxa de retorno. Ela permite você entender as deficiências do seu próprio projeto na hora de organizar os dados, de ter esse cadastro. Ela é bem clara, acho que é essa a vantagem. Apesar da técnica econométrica às vezes ser um pouco mais complicada, mas o fato de você estar comparando quem se beneficiou e quem não se beneficiou e comparar o resultado $Y$ desse grupo com esse, fica bem claro. Acho que essa é a principal vantagem, a clareza, intuição do resultado, não é uma coisa que fica dependendo de um milhão de coisas, que tem uma interpretação subjetiva de um milhão de coisas, está ali preto no branco. Essa é a principal vantagem."

\section{B) A AVALIAÇÃO ORIENTADA À TOMADA DE DECISÕES}

A avaliação orientada à tomada de decisão é aquela que coloca no centro a construção de subsídios para a tomada de decisão, inclusive envolvendo diálogos que ajudem a organização a encaminhar tais decisões ou que sejam incorporadas no próximo planejamento. Os profissionais que praticam essa abordagem são aqueles que não apenas acreditam na avaliação como subsídio para a tomada de decisão (isso todos acreditam), mas que se colocam a serviço dessa orientação, criando condições dentro do próprio processo avaliativo, para que as negociações necessárias internas à organização possam emergir e acontecer.

"Então eu tenho que construir uma aliança (...) Então aí eu deixo de ser o facilitador e passo a ser o político. Fui o diagnosticador, o avaliador, depois eu fui o facilitador de processos e por fim eu fui o político e num processo de políticas públicas ou em processos sociais eu preciso ter essas três facetas. Então como avaliador eu não posso olhar só para a avaliação, eu tenho que olhar para um processo muito mais longo do que a avaliação e se eu olhar só para o resultado de meu diagnóstico está pronto, meu plano está pronto, se vocês não implementarem é problema de vocês, eu farei meu trabalho pela metade."

A avaliação orientada à tomada de decisões é um espaço em que se privilegia o apoio à tomada de decisões dos gestores ou da equipe da iniciativa sobre ela mesma e, nesse sentido, compreende que múltiplos fatores estão presentes num processo de tomada de decisão, como informações sobre resultados, contexto político, interesses, etc. A avaliação envolve discussões sobre processos da iniciativa que devem ser afirmados ou revistos. 
A trajetória dos profissionais desta abordagem, a partir das entrevistas, está marcada por situações em que atuavam como gestores de iniciativas e se envolveram na sua avaliação ou até, passaram a ser gestores de iniciativas que anteriormente avaliaram. Ou seja, esses profissionais foram frequentemente marcados por experiências de gestão e de avaliação simultâneas.

\section{O PROCESSO DA AVALIAÇÃO ORIENTADA À TOMADA DE DECISÕES}

O processo de contextualização e construção do foco numa avaliação orientada à tomada de decisões é fortemente orientado a compreender o contexto da iniciativa e, em especial, o momento institucional. A relação entre a avaliação de uma iniciativa específica e a institucional é muito próxima, já que para ajudar o processo de tomada de decisão é necessário que a avaliação esteja bem situada institucionalmente.

Outra característica da avaliação orientada à tomada de decisões é sua presença nos vários momentos de um projeto: na sua formulação pela via do diagnóstico; na implementação, pela via do monitoramento e da avaliação de processos; e no fechamento de ciclos, pela via da avaliação de resultados e impactos. A avaliação acompanha o ciclo de planejamento-monitoramento-avaliação, compreendido como ciclo de gestão de iniciativas.

Diferente da avaliação orientada à investigação, que mostra ter uma predileção por metodologias quantitativas, a avaliação orientada à tomada de decisões maneja diferentes metodologias de investigação, assim como a avaliação orientada à aprendizagem. Porém, os profissionais que atuam dentro desta abordagem não manifestam, ao menos a partir das entrevistas, serem especialistas em metodologias específicas de investigação, ou seja, há menor especialidade nesse sentido.

Para a avaliação orientada à tomada de decisões é importante utilizar estratégias para legitimar as análises realizadas, aumentando a probabilidade de que algo seja redirecionado a partir dos achados da avaliação.

\begin{abstract}
"[escreve sobre] as coisas que foram vistas que podem dar certo que são potencialmente muito boas e sempre no caso de uma avaliação apresentando as sugestões de redirecionamento, de continuidade, de fortalecimento, enfim, eu monto esse documento. (...) Então se você não contextualizar ele não se reconhece, se você chegar simplesmente com os dados mais duros ele não vai legitimar esses dados. Então você tem que contextualizar para ele se reconhecer, para ele entender o processo todo o caminho que você fez, ou seja, vai apresentar metodologia, vai dizer as características seja da instituição, seja da localidade, enfim, seja do projeto, para só aí você começar apresentar os resultados dos dados que você coletou."
\end{abstract}

O avaliador que atua nesta abordagem tende a se envolver na discussão das recomendações e dos próximos passos do projeto, a partir da avaliação. Constrói uma 
leitura sobre a iniciativa e acredita que suas recomendações são importantes de serem adotadas para que o projeto continue se desenvolvendo e se aperfeiçoe no futuro. Dessa forma, tais profissionais tendem a não acreditar na neutralidade do avaliador, vendo-se como atuantes na revisão das estratégias da iniciativa em avaliação. "Também construí uma convicção da não neutralidade do avaliador e de seu papel como provocador de reflexão, como mediador dos diálogos, mas também como alguém que emite opinião contextualizada e fundamentada nos processos (...) [o papel do avaliador] seria ampliar e complexificar a análise de contexto da organização em questão, provocar reflexão crítica sobre identidade, cultura institucional e situação geral da organização, reflexão sobre perfil das lideranças e sobre posicionamento e estratégia de mobilização de recursos/sustentabilidade."

\section{CONSIDERAÇÕES SOBRE A ABORDAGEM}

Um limite apontado pelos próprios profissionais em relação à avaliação orientada à tomada de decisões é que o vínculo com a iniciativa e com o desejo de encontrar possíveis soluções às questões às vezes os cegam para outros aspectos. Então, a crença de que se chegou a uma mudança fundamental para a iniciativa desenvolver-se dificulta a percepção de que o que é necessário para implementar tal mudança talvez seja incompatível com a realidade e o momento em que vive uma determinada iniciativa ou organização.
"É como educação de filho. Você já passou pelo que ele está passando, você tem que dizer a ele que ele não pode fazer aquilo, mas tem certas horas que você só tem que ficar atento para a hora que ele tropeçar, você levantar se ele permitir porque se ele não permitir nem isso você pode fazer. É uma dor você ver uma organização que você está avaliando se encaminhando para um universo que você sabe que ela não vai gerar aquilo que ela quer gerar, por outro lado há organizações que divergem completamente da sua visão estratégica e mesmo que você aponte para um rumo ela vai por decisão para outro rumo que você discorda, mas é o direito daquela organização, é uma decisão dela."

Esses profissionais chamam a atenção para a incorporação de ferramentas de gestão de um setor para o outro - governo, iniciativa privada e "terceiro setor" - sem a devida reflexão sobre as especificidades de cada um deles.

De modo geral, enxergam a grande vantagem da abordagem da avaliação orientada à tomada de decisões na sua capacidade de gerar transformações a partir da avaliação, reduzindo-se o risco de termos "avaliações engavetadas". Da mesma forma, sua consideração ao contexto possibilita que as questões investigadas e o próprio processo sejam de grande relevância para o momento institucional. 
C) A AVALIAÇÃO ORIENTADA À

\section{APRENDIZAGEM}

A terceira abordagem encontrada é a da avaliação orientada à aprendizagem, cujo foco é a orientação do processo de avaliação para promoção de capacitação e aprendizagem das pessoas e organizações envolvidas, tanto sobre avaliação como outras questões mais amplas. O papel central da avaliação é oportunizar para que essa aprendizagem ocorra não apenas a partir dos achados da avaliação, mas também do processo percorrido.

"A gente está sempre muito mais focado em fazer uma avaliação que seja formativa no sentido de formar as pessoas para fazerem isso depois, que elas possam usar isso, que elas possam aprender a fazer e façam para outros projetos."

A avaliação, nesta abordagem, é oportunidade de aprendizagem para os indivíduos e para a organização sobre os processos da iniciativa, dos padrões organizacionais e dos resultados da iniciativa. Da observação e da reflexão crítica sobre esses padrões pode emergir a aprendizagem e a mudança. $O$ avaliador que atua orientado à aprendizagem se percebe como facilitador desse processo, que é particular de cada grupo e cada organização.

"Técnico é a coisa do conhecimento sobre metodologia de investigação, construir um desenho, esse papel até mesmo de estudar a avaliação, e outra coisa é você estar com um grupo identificando demandas, necessidades, interesses, jogos de interesses no contexto do projeto, o que o grupo está precisando (...) Talvez essa seja a questão (...) de que o grupo, o desenvolvimento do grupo precisa de outras coisas para além de uma investigação bem-feita. Então, primeiro é isso, ler, facilitar processos de aprendizagem até sobre o projeto, sobre a própria prática das pessoas implica coisas diferentes [do que realizar a investigação]."

Os profissionais que atuam nesta abordagem relatam frequentemente estudar sobre avaliação ou outros temas de interesse relacionados, mas ressaltam aprender também a partir da prática. Assim como acreditam na prática da avaliação como oportunidade de aprendizagem, também atribuem à própria prática vivida por eles um forte papel de aprendizagem e atualização.

"Primeiro a gente aprende muito com a prática mesmo, esse fazer traz muita aprendizagem. É fazer com o olhar do que estou aprendendo em cada afazer desse, né? Se eu dou uma oficina sobre plano de avaliação, você aprende muito com as organizações porque começa a vir coisas 'assim eu tentei e não funcionou na minha organização'. Acho que essas questões que têm da prática mesmo ajudam muito a gente a pensar em outras formas, em outras coisas."

\section{O PROCESSO DA AVALIAÇÃO ORIENTADA À APRENDIZAGEM}

Como o eixo central, a avaliação, em suas diferentes etapas, constitui oportunidade de aprendizagem para os indivíduos e as suas organizações. Na construção do foco, pensando em questões de avaliação e/ 
ou indicadores, a avaliação oportuniza um alinhamento sobre critérios e valores da organização. Por isso, a construção do foco da avaliação, seja através da explicitação de indicadores para objetivos ou perguntas de avaliação e indicadores, é feita prioritariamente juntamente com o cliente e em oficinas.

A abordagem implica de forma importante a participação dos envolvidos, já que dela depende que a avaliação seja de fato oportunidade de aprendizagem (quem aprende são sujeitos, equipes e organizações - e para isso é condição que estejam presentes). Por isso, a atuação do avaliador envolve, frequentemente, o desenvolvimento de metodologias pedagógicas para trabalhar temas que emergem. Desses profissionais escutamos que estão desenvolvendo "jogos", "dinâmicas", "exercícios" para trabalhar com o grupo envolvido na construção de indicadores, ou a coleta de informações, ou a discussão dos resultados.

De modo geral, a avaliação orientada à aprendizagem não manifestou preferências específicas por metodologias quantitativas ou qualitativas. Também nesse sentido, os profissionais que enfocam essa abordagem não são especialistas como o são os profissionais que enfocam a avaliação orientada à investigação - em metodologias ou técnicas específicas. Utilizam tanto metodologias quantitativas, como qualitativas.
O processo de discussão dos resultados pode ser iniciado a partir de uma sistematização inicial dos dados realizada pelo profissional responsável, mas a ideia principal é garantir espaços para que os envolvidos participem da análise e deem sentido a ela.

"Eu acredito hoje em dia que um relatório também deve ter a coisa descritiva, mas principalmente uma coisa muito intencional (...) Então, chegar a um relatório sintético não é que você começa com ele sintético, ele vai se tornando sintético à medida que você vai qualificando, refazendo, relendo, rediscutindo (...) Eu também tenho aprendido, nesse sentido, que um relatório tem que ter muito trabalho por trás, ter muitos passos até ficar bem-feito. Eu acho que é isso, um relatório é tão mais vivo quanto mais vezes ele foi pauta de conversas com o cliente."

\section{CONSIDERAÇÕES SOBRE A ABORDAGEM}

Um dos desafios apontados para a abordagem da avaliação orientada à aprendizagem está relacionado à necessidade de participação e ao confronto dessa oportunidade com a cultura de participação das organizações. Muitas vezes, a participação possível se restringe a escutar sujeitos como "fontes de informação", e não construindo a própria avaliação, o que limita o nível de participação e de aprendizagem na avaliação. 
Os profissionais também apontam como limite que a abordagem da avaliação orientada à aprendizagem não é de fácil compreensão para financiadores, que muitas vezes enfocam o produto da avaliação e não seu processo.

Como ganho desta abordagem, é citada especialmente sua capacidade de envolvimento dos sujeitos e da equipe que, ao longo do processo ou após a avaliação já modificam sua atuação, possibilitando melhoras imediatas nas iniciativas.

\section{Considerações finais}

O campo de avaliação no Brasil ainda é pouco claro em relação ao que marca tanto sua identidade como suas diferenças internas. Há pouco conhecimento e pouca clareza sobre as diferentes abordagens de avaliação que compõem o campo, sobre o que as unificaria e as diferenciaria dentro de um mesmo campo. Na entrevista quantitativa, por exemplo, a pergunta para os avaliadores sobre abordagens ou métodos preferidos para trabalhar gerou um conjunto tão heterogêneo de classificações e uma dispersão tão grande dos dados que impossibilitou a construção indutiva de uma classificação. Nesse sentido, será que é possível falarmos em um campo de avaliação? As entrevistas em profundidade também apontam para o mesmo aspecto: o profundo conhecimento sobre a própria prática, mas pouco sobre o campo de maneira geral.

Os entrevistados também apontam para esse equivalente do ponto de vista da "qualidade da demanda". Atualmente, também os clientes das avaliações chegam com sua demanda pouco madura, conhecem de forma limitada as opções existentes em termos de abordagens, métodos e suas consequências, assim como quais seriam as escolhas que melhor se ajustariam a suas necessidades.

A intenção de identificar diferentes abordagens não era a de diferenciar práticas e disponibilizar um "menu", mas sim de esclarecer no que consiste o próprio ato de avaliar, a partir desses diferentes "eixos de prática", por onde um mesmo avaliador pode transitar em momentos diferentes. Acreditamos que o exercício de delimitar abordagens ajuda o avaliador a criar maior consciência para poder questionar a sua própria prática: "E eu, como eu penso e faço avaliação?".

Uma maior consciência entre os avaliadores sobre as abordagens de avaliação e suas características contribui para um amadurecimento e qualificação tanto das demandas quanto das ofertas no campo de avaliação. Nessa premissa baseia-se nossa tentativa, sem negar, porém, a fluidez e indefinição do próprio fenômeno 
"campo da avaliação", e assumindo o esforço normativo implícito nessa tarefa.

A articulação e colaboração entre profissionais que atuam no campo social parece-nos um grande desafio, não somente para produzir comparações mas também para possibilitar aprendizagem e aperfeiçoamento do fazer específico do avaliar. Praticamente todos os entrevistados declararam ter pouco espaço de articulação e colaboração entre profissionais que atuam com avaliação para além de um círculo restrito de "semelhantes". As práticas de supervisão e meta-avaliação com os pares ainda são pouco frequentes, o que dificulta a crítica, aprendizagem com os pares e a própria produção de conhecimento sobre a avaliação enquanto campo disciplinar. Entrevistados apontam para a baixa difusão de conhecimento sobre avaliação enquanto uma disciplina específica e multidisciplinar. Reconhece-se a baixa frequência de escrita e publicações tendo a avaliação como objeto, para além das publicações que são estudos avaliativos tendo iniciativas, projetos, etc. como objetos. Apesar de a enorme maioria dos avaliadores ter algum vínculo com a academia, há pouco investimento na construção do campo da avaliação em relação a publicações e outros mecanismos formais de articulação e troca de conhecimento. Atualmente, reconhecem-se três iniciativas mais fortes de difusão: a Rede Brasilei- ra de Monitoramento e Avaliação e a Revista Brasileira de Monitoramento e Avaliação, que têm enfocado principalmente a troca entre profissionais que atuam no setor público; a atuação da Fundação Itaú Social na promoção de cursos e seminários sobre Avaliação Econômica de Projetos Sociais; e a parceira entre a Fundação Itaú Social e o Instituto Fonte para fortalecimento da avaliação, com realização de encontros e pesquisas mais direcionados ao campo do investimento social privado. Essas iniciativas, porém, são reconhecidas como representativas de setores e grupos específicos.

Pode-se concluir esta discussão reconhecendo que o campo de avaliação brasileira ainda é um campo jovem, em um momento de expansão e com muitos profissionais já atuando e outros tantos entrando. Cresce a importância atribuída à prática de avaliação na área social e consequentemente a atenção e consciência sobre a importância da qualidade e da competência dos profissionais deste campo. Espera-se que um maior investimento por parte dos profissionais, organizações, associações e universidades em iniciativas de formação em avaliação, pesquisa e produção de conhecimento e articulação entre avaliadores possa contribuir para a qualificação das práticas de avaliação dos avaliadores e de seus clientes e, consequentemente, para o fortalecimento das iniciativas sociais. 